\title{
Association of different HLA antigens with various toxic effects of gold salts in rheumatoid arthritis
}

\author{
M HATALA, ${ }^{3}$ A H W VAN ASSENDELFT, ${ }^{4}{\mathrm{~J} \mathrm{ILONEN},{ }^{5} \mathrm{~S} \text { JALAVA, }}^{6}$ \\ AND A TIILIKAINEN
}

From the Departments of ${ }^{1}$ Medicine and ${ }^{2}$ Medical Microbiology, University of Oulu, Oulu; ${ }^{3}$ Päivärinne Hospital, Jokirinne; the ${ }^{4}$ Department of Pulmonary Diseases, North Karelian Central Hospital, Kontioniemi; the ${ }^{5}$ National Public Health Institute, Oulu; and the ${ }^{6}$ Department of Medicine, Paimio Hospital, Preitilä, Finland

SUMMARY An association of gold induced proteinuria with HLA-D(R)3 has been reported. To investigate other possible relationships between gold toxicity and HLA antigens we studied 85 patients with rheumatoid arthritis (RA) divided into four subgroups: patients with gold induced interstitial pneumonitis, mucocutaneous lesions, proteinuria, and patients without gold toxicity. The HLA frequencies in patient groups and 283 healthy controls were compared in different pairwise combinations. Gold induced pneumonitis was associated with HLA-B40 and Dw1. An association between gold induced proteinuria and HLA-Dw3 was also seen. The increased prevalence of Dw4 in RA was observed only in the control patient group without gold induced side effects. The frequencies of HLA-B7 and Dw2 were decreased in all patient groups compared with the control population. These results further support the view of the heterogeneity of RA as manifested by the unique HLA associations with resistance and susceptibility to gold induced side effects characterising different subgroups.

Key words: HLA antigens, gold toxicity, pneumonitis.

An association between RA and HLA-D(R)4 is well documented mainly in Caucasian populations. ${ }^{1-3}$ Among immigrants from India to the United Kingdom ${ }^{4}$ and among Israeli Jews, ${ }^{5}$ however, RA is significantly associated with DR1. An increased frequency of Dw1 has also been found at least in one Caucasian population study reported from Denmark, in which the high frequency of Dw4 was confirmed. ${ }^{6}$ A 'new' HLA class II determinant, $\mathrm{MC1}$, which is associated with both DR1 and DR4 and with RA, has recently been described. ${ }^{7} \mathrm{~A}$ primary association of RA with this antigen would explain the increase of both DR1 and DR4. It has been suggested that DR4 is not primarily associated with the susceptibility of RA but depends more on the clinical course of the disease. ${ }^{89}$

A correlation has been shown in RA between gold salt intolerance, especially proteinuria, and the linkage group of HLA antigens $\mathrm{A} 1, \mathrm{~B} 8, \mathrm{Cw} 7$, and

Accepted for publication 20 August 1985.

Correspondence to Dr M Hakala, Department of Medicine, Oulu University Central Hospital, SF-90220 Oulu, Finland.
DR3. ${ }^{3}{ }^{10-12}$ In addition, a high frequency of HLAB35 has been reported in RA patients with mucocutaneous lesions of gold toxicity. ${ }^{13}$

The purpose of this study was to evaluate indirectly the pathological mechanisms of gold induced adverse effects by comparing the HLA profiles of patients with different toxic reactions to gold therapy. Special emphasis was directed towards an uncommon complication of gold therapy, i.e., drug induced interstitial pneumonitis.

\section{Patients and methods}

PATIENTS

The total number of patients in the study was 85 . Sixteen patients selected from different chest or rheumatologic units represented all patients known to have had gold induced interstitial pneumonitis in Finland since $1976 .{ }^{14}$ Six of these cases have been reported earlier. ${ }^{15-19}$ Criteria for gold induced interstitial pneumonitis were: relatively acute onset during sodium aurothiomalate therapy, diffuse bilateral pulmonary infiltrates, improvement after 
discontinuation of gold therapy or treatment with steroids, or both, and no recurrence of the disease during at least six months' follow up. The patients often presented with fever, dyspnoea, cough, and rash (Table 1). There were 11 women and five men with an age range from 20 to 72 years. Fourteen of these patients had classical or definite $\mathrm{RA},{ }^{20}$ but two fulfilled only the ARA criteria for probable RA. Nine of the 16 patients were seropositive and seven seronegative. In addition, 46 patients with classical or definite RA, who had either a history of gold induced mucocutaneous lesions or proteinuria, were retrospectively selected for the study from Päivärinne hospital and from the outpatient rheumatology clinics of the same area in Oulu, northern Finland. There were 28 women and 18 men with an age range from 25 to 77 years. Twenty six of these patients $(20$ seropositive and six seronegative) had developed mucocutaneous lesions (dermatitis in all and stomatitis in four patients), and 20 patients (13 seropositive and seven seronegative) had developed proteinuria during gold therapy. Mucocutaneous lesions or proteinuria were considered to be due to gold therapy when they presented during treatment and disappeared after therapy was discontinued. Proteinuria varied from 0.12 to $3.0 \mathrm{~g} / \mathrm{l}$. In the four patients in whom proteinuria was not quantified it was shown to be present by the dipstick method $(2+$ or more) on at least two different occasions. None of the patients with the gold induced side effects mentioned above had haematologic (i.e., leucopenia or thrombocytopenia), gastroenterologic, or other possible manifestations of gold therapy; neither did they have any other medication which could have caused the side effects. Twenty three patients from the Oulu area with classical RA, of whom all except three had seropositive disease and who had received gold salt therapy without complications for 10 years or more, formed a patient control group.

None of the patients in the study had complained of low back pain or stiffness. Thus routine $x$-ray for searching spinal or sacroiliac disease, or both, was not considered ethically justified.

CONTROLS

HLA typed controls were healthy blood donors and laboratory staff members from the Oulu area.

HLA TYPING

HLA-A, B, and C antigens were determined with a standard two stage microlymphocytotoxicity method. $^{21}$ HLA-D typing was done with local homozygous typing cells for Dw1, w2, w3, w4, w6, and w14 specificities as described earlier. ${ }^{22}$

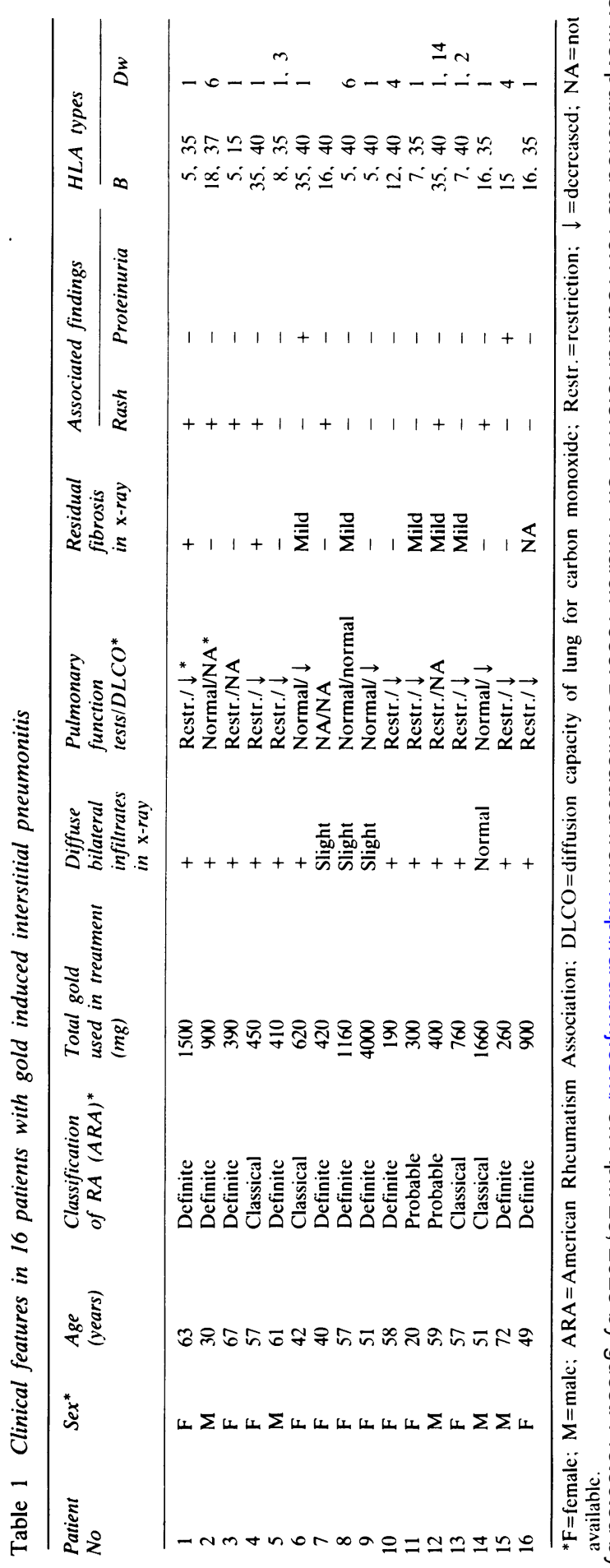


STATISTICAL ANALYSIS

Differences between groups were compared by the $\chi^{2}$ test with Yates's correction. Relative risk (RR) was calculated with the formula: $\mathrm{RR}=(\mathrm{P}+) \times(\mathrm{C}-) /$ $(\mathrm{P}-) \times(\mathrm{C}+)$, where $\mathrm{P}+$ and $\mathrm{P}-$ are the number of patients and $\mathrm{C}+$ and $\mathrm{C}-$ the number of controls positive and negative for a given HLA type respectively. ${ }^{23}$

\section{Results}

The frequencies of HLA-A, B, C, and D locus antigens in 85 patients with or without various side effects of gold salts were compared with the HLA antigen frequencies in 283 control subjects as shown in Table 2.

In patients with gold induced interstitial pneumonitis an increased frequency of HLA-B40 antigen was found as compared both with patients without side effects of gold therapy $(p=0 \cdot 01)$ and with the normal population $(p=0.001)$; the latter finding was still significant after multiplication by the number of HLA-B antigen specificities studied. The frequency of Dw1 was also increased $(p=0.02)$ as compared with patients without any gold induced side effects.

Table 2 HLA frequencies (\%) in four groups of patients with rheumatoid arthritis and in healthy control subjects

\begin{tabular}{|c|c|c|c|c|c|}
\hline \multirow[t]{2}{*}{ HLA antigen } & \multicolumn{3}{|c|}{ Gold induced side effects } & \multirow{2}{*}{$\begin{array}{l}\text { No side effects } \\
(n=23)\end{array}$} & \multirow{2}{*}{$\begin{array}{l}\text { Healthy controls } \\
(n=283)\end{array}$} \\
\hline & $\begin{array}{l}\text { Pneumonitis } \\
(n=16)\end{array}$ & $\begin{array}{l}\text { Mucocutaneous } \\
\text { lesions } \\
(n=26)\end{array}$ & $\begin{array}{l}\text { Proteinuria } \\
(n=20)\end{array}$ & & \\
\hline $\mathrm{A} 1$ & 6 & 4 & 25 & 13 & $14 \cdot 8$ \\
\hline A2 & 31 & 58 & 50 & $87 p=0.002$ & $50 \cdot 5$ \\
\hline A3 & 63 & 62 & 50 & 43 & $50 \cdot 5$ \\
\hline A9 & 19 & 15 & 10 & 13 & $24 \cdot 0$ \\
\hline A10 & 13 & 8 & 5 & 4 & 6.7 \\
\hline A11 & 6 & 12 & 0 & 9 & 3.9 \\
\hline Aw19 & 19 & 8 & 20 & 13 & $15 \cdot 2$ \\
\hline A28 & 25 & 8 & 20 & 0 & $9 \cdot 2$ \\
\hline B5 & 25 & 12 & 0 & 9 & $11 \cdot 7$ \\
\hline B7 & 13 & $8 p=0.01$ & 10 & $9 \mathrm{p}=0.03$ & $32 \cdot 9$ \\
\hline B8 & 6 & 8 & $40 \mathrm{p}=0.0009$ & 4 & $11 \cdot 3$ \\
\hline B12 & 6 & 8 & 15 & 9 & $11 \cdot 3$ \\
\hline B13 & 0 & 4 & 5 & 9 & $8 \cdot 1$ \\
\hline B14 & 0 & 0 & 0 & 0 & 0 \\
\hline B15 & 13 & 38 & 20 & $48 \mathrm{p}=0.005$ & $20 \cdot 1$ \\
\hline B16 & 19 & 12 & 0 & 9 & $8 \cdot 1$ \\
\hline B17 & 0 & 0 & 0 & 0 & $2 \cdot 8$ \\
\hline B18 & 6 & 19 & 5 & 17 & $10 \cdot 2$ \\
\hline Bw22 & 0 & 4 & 0 & 0 & $1 \cdot 4$ \\
\hline B27 & 0 & 23 & 25 & $48 p=0.0003$ & $15 \cdot 5$ \\
\hline B35 & 50 & 50 & 35 & 26 & 32.9 \\
\hline B37 & 6 & 0 & 0 & 0 & 1.4 \\
\hline \multirow[t]{2}{*}{ B40 } & $50 \mathrm{p}=0.001^{*}$ & 4 & 30 & 9 & $15 \cdot 2$ \\
\hline & & & & & $(n=138)$ \\
\hline Cw1 & 6 & 19 & 5 & 30 & $15 \cdot 9$ \\
\hline $\mathrm{Cw} 2$ & 6 & 8 & 20 & 13 & $8 \cdot 7$ \\
\hline $\mathrm{Cw} 3$ & 50 & 42 & 40 & 35 & $35 \cdot 5$ \\
\hline Cw4 & 56 & 38 & 20 & 9 & $25 \cdot 4$ \\
\hline \multirow[t]{2}{*}{ Cw6 } & 6 & 0 & 5 & 4 & $3 \cdot 6$ \\
\hline & & & $(n=19)$ & & $(n=184)$ \\
\hline Dw1 & $69 p=0.05$ & 54 & 42 & 26 & $40 \cdot 2$ \\
\hline Dw2 & 6 & 8 & 5 & 9 & $23 \cdot 9$ \\
\hline Dw3 & 6 & 8 & $37 p=0.02$ & 0 & $13 \cdot 6$ \\
\hline Dw4 & 13 & 23 & 26 & $48 \mathrm{p}=0.002$ & $17 \cdot 9$ \\
\hline Dw6 & 19 & 31 & 5 & 13 & $24 \cdot 5$ \\
\hline Dw14 & 6 & 19 & 0 & 30 & $14 \cdot 6$ \\
\hline
\end{tabular}

*The $\mathrm{p}$ values are calculated for differences in antigen frequencies between each RA group and the control group. 
The increase of HLA-B40 and Dw1 was found equally in patients from the Oulu area and other parts of the country, so the result is not invalidated by the fact that other patients and the healthy controls represented the population of the Oulu area. The B40, B35, and Dw1 frequencies still remain high when compared with those in healthy controls representing the whole nation. ${ }^{24} \mathrm{Dw} 1$ was increased also in gold induced mucocutaneous lesions. The frequencies of B8 and Dw3 antigens were increased in patients with gold therapy associated proteinuria as compared with healthy controls $(p=0.0009$ and $p=0.02$ respectively). The difference between patients with proteinuria and those without side effects was also significant for $\mathrm{B} 8(\mathrm{p}=0.01)$ and Dw3 $(p=0.006)$. The well known association of HLA-Dw4 with RA was found in patients who had received gold therapy without any side effects, $48 \%$ of these patients had Dw4. Also A2, B15, and B27 antigens were increased in this group when compared with the healthy control population. If the patient groups with different gold induced side effects are combined and considered as a whole the frequencies of Dw4 (21\%) and Dw1 (54\%) differ clearly as compared with those in the patient group without any gold induced side effects $(p=0.03$ and 0.04 respectively) (Table 3 ). B7 and Dw2 antigens were found with a decreased frequency in all groups of RA patients. In the entire group of RA patients the decreases of these antigens were significant $(p=0.00004$ and $p=0.002$, respectively).

RA patients positive for HLA-B40 were calculated to have a $10 \cdot 5$-fold and RA patients positive for Dw1 a 6-2-fold relative risk of developing gold induced pneumonitis as compared with RA patients without these antigens. For gold induced proteinuria the relative risks were $14 \cdot 7$-fold and 28.2-fold for those with antigens B8 and Dw3 respectively.

Table $3 H L A-D$ frequencies (\%) in RA patients with gold induced side effects and in long term $R A$ controls without side effects

\begin{tabular}{|c|c|c|c|}
\hline \multirow{2}{*}{$\begin{array}{l}H L A-D \\
\text { antigens }\end{array}$} & \multicolumn{2}{|c|}{ Gold-induced side effects } & \multirow[t]{2}{*}{$p$} \\
\hline & $\begin{array}{l}\text { Present } \\
(n=61)\end{array}$ & $\begin{array}{l}\text { Absent } \\
(n=23)\end{array}$ & \\
\hline Dw1 & 54 & 26 & $<0.05$ \\
\hline Dw2 & 7 & 9 & NS \\
\hline Dw3 & 16 & 0 & NS \\
\hline Dw4 & 21 & 48 & $<0.05$ \\
\hline Dw6 & 20 & 13 & NS \\
\hline Dw14 & 10 & 30 & $<0.05$ \\
\hline
\end{tabular}

\section{Discussion}

The patients with gold induced interstitial pneumonitis had a significantly increased frequency of HLA-B40 as compared with the normal population. The finding was still significant after multiplication of $p$ values by the number of HLA-B antigen specificities studied. This study suggests that HLA- \& B40 might be associated with a risk factor for gold- $\overrightarrow{0}$ induced pneumonitis or interstitial pulmonary disease, and is corroborated by the earlier report of the possible association of HLA-antigens Aw31, B7, and B40 with the familial form of idiopathic pulmonary fibrosis. ${ }^{25}$

This study lends further support to the finding that HLA-B8 and $\mathrm{D}(\mathrm{R}) 3$ antigens, which are $\vec{\nabla}$ associated with a group of various autoimmune diseases, are also a risk factor for gold induced proteinuria. ${ }^{10}$ The earlier reports have described the association with DR3, ${ }^{10-12}$ which in turn shows a very high correlation with Dw3. ${ }^{26}$ The frequency of Dw3 in our patients with proteinuria, however, was markedly lower than that of DR3 reported from England ${ }^{10}$ but agreed with the frequencies reported from Norway ${ }^{12}$ and from the United States. ${ }^{27}$ The comparison of gold induced mucocutaneous lesions with HLA antigens showed a similar trend of increased HLA-B35 and Dw1 frequencies as reported by Nuesslein et al. ${ }^{13}$ although the current differences were not statistically significant. In patients with gold induced interstitial pneumonitis there was also a high prevalence of HLA-Dw1 and B35. In Caucasian populations B35 is strongly linked with Dw1 and DR1. ${ }^{28}$ These results suggest that the pathological mechanisms of gold induced pneumonitis and mucocutaneous lesions may have some common pathways, whereas that of gold induced proteinuria probably differs from both of them and may well be similar to that in equally $\mathrm{D}(\mathrm{R}) 3$ associated membranous glomerulonephritis. ${ }^{10}$ Interestingly, only two patients $(12 \cdot 5 \%)$ within the group with gold induced pneumonitis had proteinuria, while seven of them $(44 \%)$ also had a rash.

A relationship between drug induced agranulocy- N tosis and HLA-B27 has been documented. ${ }^{29}{ }^{30}$ In $\mathrm{N}^{3}$ our material, conversely, it seemed that HLA-B27 ج might even be a protective factor for gold induced $O$ lung injury. In an earlier report patients with or without side effects of gold therapy, however, had $\stackrel{\oplus}{?}$ an equal frequency of HLA-B27. ${ }^{31}$ The high frequency of HLA-B27 in patients without gold intolerance found in this report agrees with the earlier observations of the association between RA and HLA-B27 in a Finnish RA population. ${ }^{32}$ Our current patient series is being analysed to ascertain 
whether the increase of B27 is secondary to the increase of a DR4 and Dw14 bearing haplotype frequently occurring in the Finnish population, or whether B27 has some independent influence in a form of RA.

In conclusion we found that HLA-B40 was significantly increased in patients with gold induced pneumonitis. There was also a high prevalence of HLA-Dw1 among patients with gold toxicity, especially those showing pulmonary or mucocutaneous manifestations. The combined patient group with different gold induced side effects and the patient group without any side effects differed in regard to HLA-Dw1 and Dw4. The increased prevalence of Dw4 in RA was seen only in the patients without gold induced side effects. The results further support the view of the heterogeneity of $\mathrm{RA}^{89}$ as manifested by the unique HLA associations with resistance and susceptibility to gold induced side effects characterising different subgroups. The decreased frequency of HLA-B7 and Dw2 (also representing a well known positive linkage disequilibrium) in RA was the most consistent finding in all patient groups. Because of the small number of patients in different groups a statistically valid decrease of HLA-Dw2 could not be confirmed in any patient group. In the whole patient sample, however, the frequency of HLA-Dw2 was significantly lower $(p=0.002)$ than in healthy controls, supporting the view that HLA-D(R)2 has a protective effect against a susceptibility to RA. ${ }^{3}$

The authors thank the following doctors and hospitals for contributing patients to the study: Matti Torkko. Kuopio University Central Hospital: Olli Koivisto and Risto Hämeenkorpi. Päivärinne Hospital; Per Franzén, Mjölbolsta Hospital; Aaro Kajander. Rhcumatism Foundation Hospital. Hcinola: Ritva Riihimäki. Tiuru Hospital; Timo Karakorpi and Matti Paananen. Kinkomaa Hospital. This work was supported by grants from the W J Kaipainen fund of Oulun Yliopiston Tukisäätiö. Sigrid Jusélius Foundation. and the Jalmari and Rauha Ahokas Foundation. Finland.

\section{References}

1 Stastny P. Mixed lymphocyte culture typing cells from patients with rheumatoid arthritis. Tissue Antigens 1974; 4: 571-9.

2 Stastny P. Association of the B-cell alloantigen DRw4 with rheumatoid arthritis. $N$ Engl J Med 1978; 298: 869-71.

3 Panayi G S, Woolcy P. Batchelor J R. Genetic basis of rheumatic disease: HLA antigens, disease manifestations and toxic reactions to drugs. $\mathrm{Br}$ Med J 1978; ii: 1326-8.

4 Woodrow J C, Nichol F E, Zaphiropoulos G. DR antigens and rheumatoid arthritis: a study of two populations. Br Med J 1981 ; 283: 1287-8.

5 Schiff B, Mizrachi Y, Orgad S. Yaron M, Gazit E. Association of HLA-Aw31 and HLA-DR1 with adult rheumatoid arthritis. Ann Rheum Dis 1982; 41: 403-4.

6 Thomsen M, Morling N. Snorrason E. Svejgaard A. Soerensen
S F. HLA-Dw4 and rheumatoid arthritis. Tissue Antigens 1979; 13: $56-60$

7 Duquesnoy R J, Marrari M, Hackbarth S, Zeevi A. Serological and cellular definition of a new HLA-DR associated determinant, MC1, and its association with rheumatoid arthritis. Hum Immunol 1984; 10: 165-76.

8 De Jongh B M, van Romunde L K J, Valkenburg H A, de Lange G G, van Rood J J. Epidemiological study of HLA and GM in rheumatoid arthritis and related symptoms in an open Dutch population. Ann Rheum Dis 1984; 43: 613-9.

9 Young A, Jaraquemada D, Awad J, et al. Association of HLADR4/Dw4 and DR2/Dw2 with radiologic changes in a prospective study of patients with rheumatoid arthritis. Arthritis Rheum 1984; 27: 20-5.

10 Wooley P H, Griffin J, Panayi G S, Batchelor J R, Welsh K I, Gibson T J. HLA-DR antigens and toxic reaction to sodium aurothiomalate and D-penicillamine in patients with rheumatoid arthritis. $N$ Engl J Med 1980; 303: 300-2.

11 Bardin T. Dryll A. Debeyre N, et al. HLA system and side effects of gold salts and D-penicillamine treatment of rheumatoid arthritis. Ann Rheum Dis 1982; 41: 599-601.

12 Gran J T. Husby G. Thorsby E. HLA DR antigens and gold toxicity. Ann Rheum Dis 1983: 42: 63-6.

13 Nuesslein H G, Jahn H, Lösch G, Guggenmoos-Holzmann I, Leibold W. Kalden J R. Association of HLA-Bw35 with mucocutaneous lesions in rheumatoid arthritis patients undergoing sodium aurothiomalate therapy. Arthritis Rheum 1984; 27: 833-6.

14 Savilahti M. Pulmonary complication following use of gold salts. Ann Med Int Fenn 1948; 37: 263-6.

15 Tala E. Jalava S. Nurmela T. Vuori K. Pulmonary infiltrates associated with gold therapy. Scand J Rheumatol 1979; 8: 97-100.

16 Jalava S, Kalimo H, Ruuskanen O, Tala E. Pulmonary reactions induced by gold therapy. Scand J Rheumatol 1979; 8: 192.

17 Terho E O. Torkko M. Valta R. Pulmonary damage associated with gold therapy. Scand J Respir Dis 1979; 60: 345-9.

18 Nickels J, van Assendelft A H W. Tukiainen P. Diffuse pulmonary injury associated with gold treatment. Acta Pathol Microbiol Immunol Scand [A] 1983: 91: 265-7.

19 Franzén P. Pettersson T. Alveolitis during chrysotherapy for rheumatoid arthritis. Acta Med Scand 1983; 214: 249-51.

20 Ropes M W. Bennett G A. Cobb S. Jacox R. Jessar R A. Revision of diagnostic criteria for rheumatoid arthritis. Bull Rheum Dis 1958; 9: 175-6.

21 Turunen O, Lundqvist C. Julin M. Holmlund G. Tiilikainen A. de la Chapelle A. Stimulatory and cytotoxic activity on human adult and fetal lymphocytes by heterologous antihuman fetal lymphocyte sera. Transplant Proc 1979; 27: 304-8.

22 Ilonen J. Lagerstedt A. Koskimies S. Reunanen M. HLA-Dw1 and $\mathrm{BfF}$ as protective markers in multiple sclerosis. $J$ Neuroimmunol 1983: 5: 283-8.

23 Svejgaard A. Jersild C. Staub Nielsen L, Bodmer W F. HL-A antigens and disease. Tissue Antigens 1974; 4: 95-105.

24 Tiilikainen A, Lassus A, Karvonen J, Vartiainen P, Julin M. Psoriasis and HLA-Cw6. Br J Dermatol 1980; 102: 179-84.

25 Javaheri S, Lederer D H, Pella J A, Mark G J, Levine B W. Idiopathic pulmonary fibrosis in monozygotic twins. The importance of genetic predisposition. Chest 1980; 78: 591-4.

26 Nousiainen H, Thoresen A B. Bratlic A, Winther N, Moen T, Thorsby E. Identification and correlation of HLA-D and DR specificities by Workshop reagents. In: Terasaki $\mathrm{P} I$, ed. Histocompatibility testing 1980. Los Angeles: UCLA Tissue Typing Lab, 1980: 889-90.

27 Barger B O, Acton R T, Koopman W J, Alarcon G S. DR antigens and gold toxicity in white rheumatoid arthritis patients. Arthritis Rheum 1984; 27: 601-5.

28 Baur M P. Danilovs J A. Population analysis of HLA-A, B, C, 
DR and other genetic markers. Joint report. In: Terasaki P I, ed. Histocompatibility testing 1980. Los Angeles: UCLA Tissue Typing Lab, 1980: 955-93.

29 Schmidt K L, Mueller-Eckhardt C. Agranulocytosis, levamisole and HLA-B27. Lancet 1977; ii: 85.

30 Veys E M, Mielants H, Rosenthal M. Agranulocytosis, levamisole and HLA-B27. Lancet 1977; ii: 764.

31 Jalava S, Luukkainen R, Hämeenkorpi R, Helve T, Isomäki H.
Some characteristics of RA patients with and without side effects due to gold treatment. Scand J Rheumatol 1977; 6: 206-8.

32 Isomäki H, Nissilä M, Koota K, Martio J, Tiilikainen A. HL-A 27 and rheumatoid arthritis. Lancet 1974; ii: 1212-3.

33 Stastny P. Rheumatoid arthritis. Joint report. In: Terasaki P I, ed. Histocompatibility testing 1980. Los Angeles: UCLA Tissue Typing Lab, 1980: 681-6. 